\title{
SEPARATION OF PROTEINS IN THE EPIDIDYMAL FLUID OF THE RAM*
}

\author{
EUGENIA ALUMOT $\uparrow \uparrow$ Y. LENSKY $\ddagger$ AND H. SCHINDLER $\dagger$ \\ $\uparrow$ Volcani Institute of Agricultural Research, and \\ $\ddagger$ Faculty of Agriculture, Hebrew University of Jerusalem, Rehovot, Israel
}

(Received 12th fuly 1970)

\begin{abstract}
Summary. Proteins of ram epididymal fluid, seminal plasma, accessory gland fluid and blood serum were fractionated by electrophoresis. Nineteen bands of different mobilities were observed by disc electrophoresis. Immunoelectrophoresis revealed sixteen precipitation arcs in epididymal fluid and seminal plasma and fourteen in blood serum, following absorption with the antiserum against epididymal fluid. These results indicate that most of the epididymal fluid and seminal plasma proteins of the ram have antigens in common with blood serum.
\end{abstract}

\section{INTRODUCTION}

The composition of the protein fraction in the fluids of the reproductive organs has been studied in different species. Quinlivan (1968) found that the proteins of human seminal plasma are derived mainly from the blood serum. Sedlakova, Dostal \& Matousek (1968) identified serum albumin in the epididymal fluid of pigs and assumed that other proteins also derive from blood serum. In the ram, the proteins of the rete testis fluid were fractionated by Johnson \& Setchell (1968), and those of the seminal plasma by Bennet (1965). No information is available on the proteins of ram epididymal fluid. It was the purpose of this study to provide some information on this subject and to compare the proteins in the fluids of the different reproductive organs with blood serum proteins.

\section{MATERIALS AND METHODS}

\section{Sampling}

Epididymal fluid was obtained from rams with a fistula of the vas deferens (Tadmor \& Schindler, 1966), whole semen from intact rams using an artificial vagina and accessory gland fluid from vasectomized rams by electroejaculation.

Spermatozoa were removed from the epididymal and ejaculated semen, after dilution with an equal volume of saline, by centrifugation at $4300 \mathrm{~g}$. The accessory gland fluid was analysed directly. Blood serum was obtained by centrifugation of whole blood at $2200 \mathrm{~g}$.

* Contribution from The Volcani Institute of Agricultural Research (NUIA), Bet Dagan, Israel. 1970 Series, No. 1750-E. 
Some of the samples were stored at $-20^{\circ} \mathrm{C}$. No differences in fractionation were obtained between fresh and stored samples.

\section{Disc electrophoresis}

The method of Davis (1964) for human serum was followed. Samples of 50 to $100 \mu \mathrm{l}$ were mixed with 0.5 to $1.0 \mathrm{ml}$ large-pore solution and triplicate aliquots of 0.10 to $0.15 \mathrm{ml}$ per tube were analysed.

The optimal quantities per tube were: blood serum, $5 \mu \mathrm{l}$; epididymal fluid and seminal plasma, 6 to $7 \mu \mathrm{l}$ each; and accessory gland fluid, $30 \mu \mathrm{l}$ of the original fluid. The separation took about $1 \mathrm{hr}$, applying $2 \mathrm{~mA}$ per tube until the marker left the upper gel and $3.5 \mathrm{~mA}$ per tube in the small-pore gel. This method resulted in a fairly good separation and was not improved by using gels of different concentrations as proposed by Wright \& Mallmann (1966).

The numbering of bands was carried out according to their $R_{\mathrm{X}}$ values, which were calculated as the distance travelled by the band, divided by the length of the small-pore gel (from the origin to the tracing dye). Bands with equal $R_{\mathrm{X}}$ values were assigned the same band number. The intensity of the staining was determined by photographing the gels, after which the negatives were projected by an enlarger on to a positive film, which was scanned with a densitometer attachment to the model RB Analytrol integrating scanner (Beckman, Calif.).

\section{Preparation of antisera}

The centrifuged epididymal fluid was emulsified in Freund's adjuvant (Difco, Detroit) and injected subcutaneously into rabbits at several sites along the vertebral column. Two weeks later, booster injections were administered. The animals were exsanguinated and the antisera were frozen at $-20^{\circ} \mathrm{C}$, after the addition of a drop of $0.01 \%$ merthiolate. Using these antisera, up to sixteen epididymal fluid antigens were detected in immunoelectrophoresis experiments.

\section{Immunoelectrophoretic analysis}

The procedure of Grabar \& Williams (1955), modified by Scheidegger (1955), was followed. Standard microscope slides were covered with $2 \mathrm{ml}$ of $1 \%$ agar (Difco, Special 'Noble') in barbital-acetate buffer at $\mathrm{pH} 8.6$; $\mathrm{I}=0.05$. The electrophoresis was carried out at $100 \mathrm{~V}$, applying $3 \mathrm{~mA}$ per slide for 75 min. Prints were made in an enlarger, using the dried slides-stained with Amido Black-as negatives.

\section{Gel diffusion}

Following separation by disc electrophoresis, the unfixed acrylamide gel columns were cut into halves. One half was deposited on $1 \%$ agar, prepared as described in the foregoing paragraph. The antiserum against epididymal fluid was put into two parallel troughs on both sides of the gel. The diffusion took 5 days at room temperature. The other half of the gel, serving for reference, was stained for proteins.

\section{RESULTS}

Seventeen bands were observed in samples of epididymal fluid and seminal 
plasma, fourteen in accessory gland fluid and sixteen in blood serum. Nineteen bands were numbered according to the $R_{\mathrm{X}}$ values. The fractionation records obtained by disc electrophoresis are presented in Text-fig. 1. In some records, distinct fractions very close to each other were read as one peak by the scanner. The numbers refer, therefore, to separate bands that could be seen in the gels. Although most of the nineteen bands were present in each of the samples, their relative concentration was different. Band 16 of albumin was predominant in

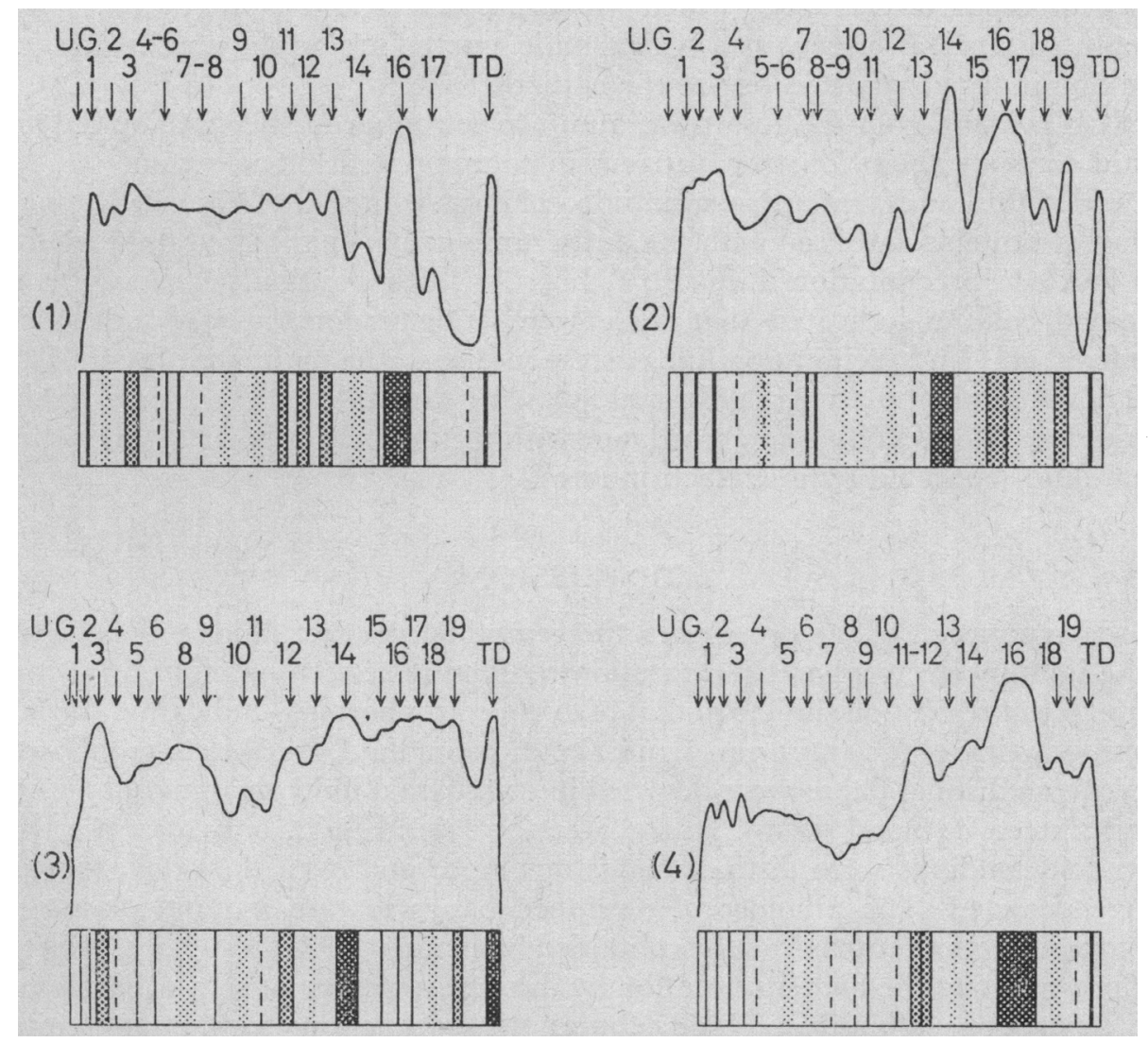

TEXT-FIG. 1. Disc electrophoretograms and densitometric tracings. UG, upper gel; TD, tracking dye. (1) Epididymal fluid, $6 \mu \mathrm{l}$; (2) seminal plasma, $7 \mu \mathrm{l}$; (3) accessory gland fluid, $30 \mu \mathrm{l}$; (4) blood serum, $5 \mu \mathrm{l}$.

the blood serum (possibly overlapping Bands 15 and 17) and in epididymal fluid but in the accessory gland fluid, its concentration did not differ from that of the other protein bands. The prealbumin Band 18 was not detected in the epididymal fluid.

A characteristic difference between the three fluids of the reproductive tract was found in Band 14. The intensity of this band was lower in the epididymal fluid than in the seminal plasma, where it competes with albumin. In accessory gland fluid, this band was one of the most concentrated. It appears, therefore, 
that Bands 14 and 18 are contributed to the seminal plasma mainly by the accessory gland fluid.

The results of immunoelectrophoretic analysis of epididymal fluid, seminal plasma and blood serum absorbed with the antiserum against epididymal fluid, are presented in Plate 1, Fig. 1. Sixteen precipitation lines were detected in epididymal fluid and seminal plasma and fourteen in blood serum. The precipitation arcs were distributed over three major groups of different mobilities: anodic (A), cathodic (B) and near the origin (C). In all three fluids, most of the arcs appeared in Group $\mathrm{C}$, which was composed of slowly migrating components. Albumin is present as a typical wide, curved arc on the anodic side, and $\gamma$-globulin as a long, thin one at the cathodic side.

It is evident from the results of immunoelectrophoresis that the epididymal fluid contains about fourteen antigens in common with blood serum.

Gel diffusion of unfixed acrylamide columns containing separated seminal plasma proteins absorbed with the antiserum against epididymal fluid resulted in fourteen precipitation lines (Pl. 1, Fig. 2). Their position in relation to the stained column indicated that these were antigens located as bands in the unfixed gel. No precipitation line corresponding to the main prealbumin Band 18 of the seminal plasma was formed following the use of the antiserum against epididymal fluid. This is in accordance with the absence of Band 18 in epididymal fluid separated by disc electrophoresis.

\section{DISCUSSION}

Good separation of the proteins in the reproductive tract fluids was achieved. The immunoelectrophoretic separation resulted in sixteen precipitation arcsa degree of resolution similar to that of disc electrophoresis-indicating the high antibody titre of the antiserum against epididymal fluid. By disc electrophoresis, seventeen distinct bands were detected in epididymal fluid and seminal plasma, and sixteen in blood serum. In the accessory gland fluid, only after applying five-fold amounts were distinct bands observed, and even then only fourteen were detected. The presence of seventeen bands in ram seminal plasma, as compared to six protein fractions obtained by Bennet (1965) by agar gel electrophoresis, shows the higher resolution by disc electrophoresis. Using this method of separation, Quinlivan (1968) found fifteen fractions in human seminal plasma.

The protein pattern of the different fluids separated by disc electrophoresis was not identical and the relative concentrations of the bands were characteristic for each fluid. Band 14 was more concentrated in accessory gland fluid and in seminal plasma than in blood serum and epididymal fluid. The prealbumin Band 18, which was absent or of very low intensity in the epididymal fluid, was present at a relatively high concentration in the accessory gland fluid and was distinct in the seminal plasma and blood serum. The protein pattern of seminal plasma reflects the contribution of the fluids from both the epididymis and the accessory glands.

The selective uptake of serum proteins by the reproductive organs of the ram was suggested by Johnson \& Setchell (1968). In their work, only some of 


\section{PIATE}

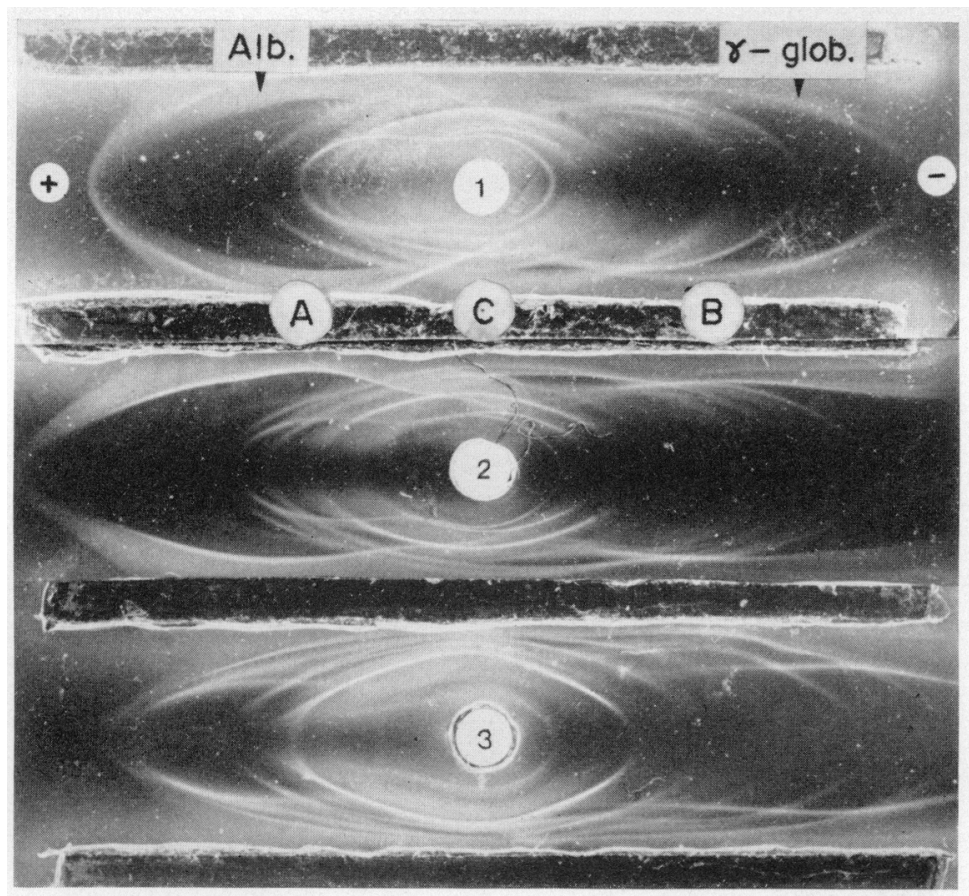

Fir. 1. Immunoclectrophoretic analysis of epididymal fluid (1), blood serum (2) and seminal plasma (3) absorbed with antiscrum against epididymal fluid. There are three major groups of different mobilities: A anodic, B- cathodic, $C:$ near the origin.

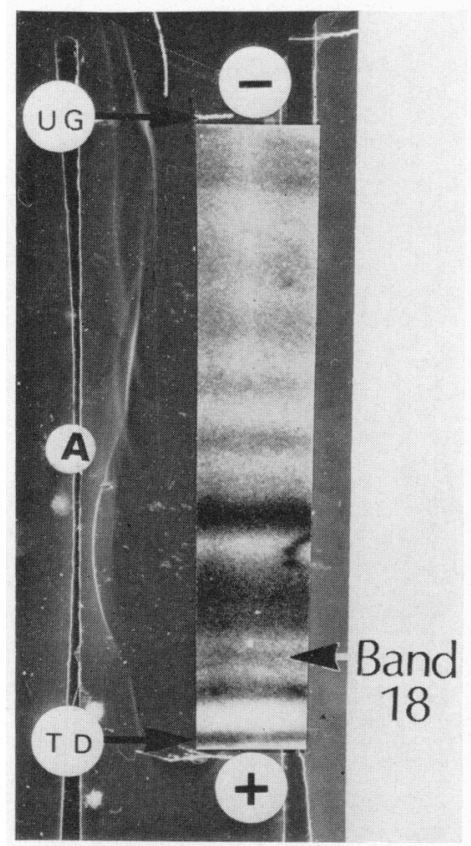

Fif: 2. Disc elcctrophoresis gel diffusion of ram seminal plasma reacting with antiserum agairst epididymal fluid. A photograph of a stained column has been superimposed to compare the disc electrophoresis bands with precipitation lines formed in agar. UG, upper gel; TI), tracking dye; $A$, trough with the antiserum. 
the protein fractions from the rete testis fluid shared common antigens with blood serum. A similar conclusion can be drawn from the study on transaminases in the epididymal fluid and seminal plasma of the ram. The activity of one of the enzymes (GOT) was found to exceed many times that of the blood, whereas another enzyme (GPT) was not active, despite its presence in the blood (Alumot \& Schindler, 1965).

Similar mobilities of bands in disc electrophoresis are not a proof of identity of the proteins from different sources. Immunological methods are more specific, showing the presence of common antigens in the different fluids. The immunoelectrophoretic analysis revealed the presence of fourteen precipitation arcs in blood serum, as compared with sixteen arcs in epididymal fluid, when absorbed with antiserum against epididymal fluid. This indicates that most of the epididymal fluid antigens are common with those of the blood serum.

It seems that the blood serum is the main source of proteins in the epididymal and accessory gland fluids and in seminal plasma of the ram. A selective uptake from the blood serum may explain the differences existing between their protein concentration.

\section{ACKNOWLEDGMENTS}

This research has been financed in part by a grant made by the United States Department of Agriculture under PL 480. We gratefully acknowledge the skillful technical assistance of Mr E. Mandel and Mr B. Kalinski.

\section{REFERENCES}

Alumot, E. \& Schindler, H. (1965) Transaminases in the epididymal fluid of the ram. F. Reprod. Fert. $10,261$.

BenNet, J. P. (1965) Quantitative comparisons of the proteins of the seminal plasma of bull, ram, rabbit and boar by agar gel electrophoresis. F. Reprod. Fert. 9, 217.

Davis, B. J. (1964) Disc electrophoresis. II. Method and application to human serum proteins. Ann. N.Y. Acad. Sci. 121, 404.

Grabar, P. P. \& Williams, C. A. (1955) Méthode immuno-électrophorétique d'analyse de substances de mélanges antigéniques. Biochim. biophys. Acta, 17, 67.

Johnson, M. H. \& Setchell, B. P. (1968) Protein and immunoglobulin content of rete testis fluid of rams. F. Reprod. Fert. 17, 403.

Quinutvan, W. L. G. (1968) Analysis of the proteins in human seminal plasma. Archs Biochem. Biophys. 127, 680 .

Scheidegarr, J. J. (1955) Une micro-méthode de l'immuno-électrophorèse. Int. Archs Allergy appl. Immun. 7, 103.

Sedrakova, E., Dostal, J. \& Matousek, J. (1968) Serum albumin in pig epididymis. Comp. Biochem. Physiol. 26, 143.

TAdmor, A. \& Schindler, H. (1966) Establishment of a fistula in the vas deferens of rams. Israel $\mathcal{F}$. agric. Res. (Ktavim) 16, 157.

Wright, G. L. \& Mallmann, N. (1966) Differential disc electrophoresis of serum proteins. Proc. Soc. exp. Biol. Med. 123, 22. 